\title{
Struktur Komunitas Odonata di Kawasan Wana Wisata Curug Semirang Kecamatan Ungaran Barat, Semarang
}

\author{
Frendi Irawan, Mochamad Hadi dan Udi Tarwotjo \\ Laboratorium Ekologi dan Biosistematik, Departemen Biologi \\ Fakultas Sains dan Matematika, Universitas Diponegoro, Semarang \\ Jln. Prof. Soedarto, SH., Tembalang, Semarang, 50275, \\ Telp: (024) 7474754; Fax: (024) 7474754 \\ E-mail: frendi311@gmail.com
}

\begin{abstract}
Dragonflies role as a predator in an ecosystem and become a healthy aquatic bio-indicators related to the life cycle. The diversity of habitat, food and predators affect community structure dragonfly. This study aims to determine the composition and community structure dragonfly morning and afternoon as well as the relationship with the physical environmental factors on four habitat in Semirang waterfall. Research using transect Point Count method. Statistically, the biodiversity of odonata in each habitat is significantly different. The results shows there are 15 species from 10 Family in morning observations and 12 species of 6 Family in afternoon observations, with a total of 17 species of 10 family of odonata. Biodiversity in each station is low to moderately with high evenness. The highest abundance found in river habitat without the canopy during the afternoon that Vestalis luctuosa (61.29\%), while the lowest abundance found in the the canopied river habitat when afternoon that is Drepanosticta spatulifera $(1.33 \%)$. Common species at area of Semirang waterfall are Euphaea variegata, Orthetrum sabina and Vestalis luctuosa. Endemic species at area of Semirang waterfall are Heliocypha fenestrata, Drepanosticta spatulifera and D. sundana.
\end{abstract}

Key words : Community structure, Odonata, Semirang waterfall

\begin{abstract}
Abstrak
Capung berperan sebagai pemangsa dalam suatu ekosistem dan menjadi bioindikator perairan yang sehat terkait siklus hidupnya. Keragaman habitat, makanan dan predator mempengaruhi struktur komunitas capung. Penelitian ini bertujuan untuk mengetahui komposisi dan struktur komunitas capung pagi dan sore serta hubungan dengan faktor fisik lingkungan pada 4 habitat di Wana Wisata Curug Semirang. Penelitian menggunakan metode Transek Point Count. Secara umum keanekaragaman capung di tiap habitat berbeda nyata. Didapatkan 15 Spesies dari 10 Famili capung pada pengamatan pagi dan 12 Spesies dari 6 Famili pada pengamatan sore, dengan total 17 Spesies dari 10 Famili capung. Keanekaragaman Spesies capung di tiap stasiun rendah hingga sedang dengan kemerataan tinggi. Kelimpahan capung tertinggi terdapat pada habitat sungai tanpa kanopi saat sore yaitu Vestalis luctuosa (61,29\%), sedangkan kelimpahan capung terendah ditemukan di habitat sungai berkanopi saat sore yaitu Drepanosticta spatulifera (1,33\%). Spesies umum di WWCS yaitu Euphaea variegata, Orthetrum sabina dan Vestalis luctuosa. Spesies endemik di WWCS yaitu Heliocypha fenestrata, Drepanosticta spatulifera dan D. sundana.
\end{abstract}

Kata kunci : Struktur komunitas, Capung, Curug Semirang

\section{PENDAHULUAN}

Indonesia dikenal sebagai negara tropis dengan keanekaragaman hayati yang tinggi (Megabiodiversity) di dunia. Kondisi geografis Indonesia yang berpulau-pulau dan merupakan pertemuan kawasan biogeografi antara
Oriental dan Australasia menjadikan Indonesia melimpah akan keanekaragaman spesies flora dan fauna. Banyaknya pulau tersebut menjadikan spesies flora dan fauna banyak yang terisolir dan lambat laun memunculkan spesies endemik. Hal tersebut akan 
memperkaya keanekaragaman hayati Indonesia, khususnya Ordo Odonata atau capung.

Capung merupakan serangga terbang yang hidupnya tidak terlepas dari keberadaan perairan. Capung meletakan telurnya pada air atau pada tanaman air. Capung (fase nimfa) hidup didalam perairan yang sehat sehingga capung dapat dijadikan bioindikator kondisi perairan. Hidup capung juga tidak terlepas dari tutupan vegetasi yang digunakan untuk meletakan telur pada tumbuhan di perairan, molting (perubahan dari bentuk nimfa ke capung dewasa), kawin dan untuk tempat hinggap capung dewasa saat beristirahat. Capung saat nimfa ataupun dewasa berperan sebagai predator yang memangsa serangga kecil seperti nyamuk atau jentiknya, belalang, wereng, kupu-kupu dan serangga lainnya bahkan sesama capung dan spesiesnya sendiri (kanibalisme).

Wana Wisata Curug Semirang dikelola oleh Perum Perhutani dengan kawasan seluas 10 Ha, terletak di Dusun Gintungan, Desa Gogik, Kecamatan Ungaran Barat, Kabupaten Semarang. Wana Wisata Curug Semirang terletak di lereng timur laut gunung Ungaran dengan ketinggian lokasi berkisar antara 500 $800 \mathrm{~m}$ dpl. Memiliki kemiringan lahan yang bervariasi, memiliki beberapa tipe vegetasi, tutupan hutan dan dialiri oleh sungai yang bersumber dari gunung Ungaran yang sangat berpotensi sebagai habitat dari berbagai spesies capung. Beragamnya tipe habitat dengan variasi elevasi berpotensi sebagai tempat tinggal capung yang sangat beragam jenisnya.

Tujuan penelitian ini yaitu untuk mengetahui komposisi dan struktur komunitas capung pagi dan sore serta hubungan dengan faktor fisik lingkungan pada 4 habitat di Wana Wisata Curug Semirang..

\section{BAHAN DAN METODE Waktu dan Tempat}

Penelitian dilaksanakan di kawasan Wana Wisata Curug Semirang Kecamatan Ungaran Barat, Semarang. Tempat penelitian dibagi menjadi 4 stasiun pengamatan yaitu kebun kopi (St.1), sungai tanpa kanopi (St.2), hutan sekunder (St.3) dan Sungai berkanopi (St.4). Proses identifikasi lanjut dilakukan di laboratorium Ekologi dan Biosistematik Departemen Biologi Fakultas Sains dan Matematika Universitas Diponegoro (UNDIP).

Penelitian dilaksanakan pada bulan Oktober hingga November 2016. Pengamatan pagi hari pukul $06.30-09.20$ WIB dan sore hari pukul $13.00-15.50$ WIB. Tiap stasiun dilakukan pengamatan selama 20 menit, estimasi lama perjalanan tiap stasiun 30 menit.

\section{Alat dan Bahan}

Alat yang digunakan yaitu jaring serangga, kertas papilot, kotak spesimen, kamera, multifunction meter, GPS, alat tulis dan kapas. Bahan yang digunakan adalah kloroform.

\section{Cara Kerja}

Penelitian ini dilakukan dengan menggunakan metode transek Point Count yaitu perpaduan antara metode transek dengan metode titik hitung. Garis transek dibuat dengan mengikuti badan sungai sejauh 900 meter. Menurut Smallshire \& Beynon (2010), untuk survey capung garis transek sebaiknya mengikuti tepi sungai sejarak yang sudah ditentukan. Kemudian dilakukan pendataan dengan menghitung spesies yang teramati selama 20 menit pada stasiun yang sudah ditentukan. Spesies yang belum teridentifikasi dilapangan akan di identifikasi lebih lanjut di laboratorium.

Parameter lingkungan diukur dengan menggunakan Multifunction meter. Parameter yang diukur yaitu Suhu udara, Intensitas cahaya, Kecepatan angin dan Kelembaban udara. 
Analisis data dihitung menggunakan indeks kelimpahan,keanekaragaman ShannonWiener, kemerataan dan Uji t-Hutchinson serta analisis hubungan faktor abiotik dengan biotik menggunakan korelasi Spearman.

\section{HASIL DAN PEMBAHASAN}

Hasil penelitian dari 4 stasiun didapatkan 15 Spesies dari 10 famili capung pada pengamatan pagi dan 12 spesies dari 6 famili pada pengamatan sore. Total spesies yang didapatkan yaitu 17 spesies dari 10 famili (Tabel 1.). Terdapat variasi komposisi spesies pada tiap stasiun penelitian. Beberapa spesies dapat dijumpai lebih dari satu stasiun pengamatan dan bahkan di semua stasiun pengamatan. Vestalis luctuosa dan Euphaea variegata dijumpai di semua stasiun penelitian baik pagi maupun sore. Orthetrum sabina dijumpai hampir di semua stasiun pengamatan kecuali pada habitat kebun kopi.

Spesies yang didapatkan pada penelitian ini tergolong tinggi, Irawan dan Hadi (2015) pada penelitian sebelumnya mendapatkan 16 spesies di Kawasan Wana Wisata Curug Semirang, Herlambang (2016) mendapatkan 19 spesies pada penelitian Struktur Komunitas Capung Di Kawasan Wana Wisata Curug Lawe-Benowo Ungaran Barat, sedangkan Rizal (2014) mendapatkan 18 spesies capung dalam penelitian struktur komunitas capung di Kawasan Rawa Pening, Ambarawa. Perbedaan banyak spesies yang didapatkan dipengaruhi oleh beberapa faktor seperti kondisi habitat, tipe habitat, kondisi kemofisis habitat serta cuaca atau musim.

Beberapa spesies dapat dijumpai pada musim tertentu, Heliocypha fenestrata dapat dijumpai pada musim penghujan karena merupakan kondisi yang tepat untuk molting dari nimfa. Genus Drepanosticta terdata populasi terbanyak pada musim penghujan (Herlambang, 2016). Habitat tertentu akan mempengaruhi keberadaan suatu spesies, beberapa spesies dari famili Gomphidae memilih sungai jeram dengan substrat berpasir sebagai habitatnya. Sedangkan Idionix montana hidup pada habitat hutan pada ketinggian 150 - $1000 \mathrm{~m}$ dpl (Dow, 2009b).

Beberapa capung endemik Jawa didapatkan pada penelitian ini yaitu Heliocypha fenestrata, Drepanosticta spatulifera dan $D$. sundana. Menurut Lieftinck (1934) dalam Whitten (1999), Spesies Heliocypha (Rhinocypha) fenestrata merupakan endemik di Jawa dan Bali. Di Jawa terdapat lima anggota Genus Drepanosticta dan endemik yaitu Drepanosticta bartelsi, $D$. gazella, D. siebersi, D. spatulifera dan $D$. sundana. Pada penelitian sebelumnya (Irawan dan Hadi, 2015), genus Drepanosticta yang didapatkan yaitu tiga spesies $D$. gazella, $D$. spatulifera dan $D$. sundana, dua anggota yang lain diketahui hanya dijumpai di Pegunungan Tengger pada ketinggian $1700 \mathrm{~m}$ dpl yaitu Drepanosticta siebersi dan dijumpai di Jawa Barat pada habitat hutan gelap dengan jurangjurang pada pantai selatan yaitu $D$. bartelsi.

Tingkat dominansi capung dapat dilihat dari kelimpahan relatif tiap spesies capung pada suatu habitat. Keberadaan jumlah spesies dalam suatu habitat akan berpengaruh pada nilai dominansi. Semakin sedikit jumlah spesies maka nilai dominansi akan tinggi, begitu pula sebaliknya. Odum (1971) berpendapat jika indeks kelimpahan suatu spesies tinggi berarti spesies tersebut mampu bertahan dan beradaptasi terhadap faktor pembatas yang ada.

Vestalis luctuosa ditemukan di semua habitat dan termasuk kategori sebagai spesies dominan pada habitat sungai tanpa kanopi (St. 2) dengan indeks kelimpahan tertinggi 61,29 $\%$ pada sore hari dan $51,72 \%$ pada pagi hari. Jenis yang juga ditemukan di semua habitat yaitu Euphaea variegata dengan indeks kelimpahan pada habitat sungai tanpa kanopi saat sore hari $32,25 \%$. Kedua spesies tersebut ditemukan mengelompok dan terkadang terdapat pada satu daerah teritorial di semua 
aliran sungai, terutama spesies $V$. luctuosa yang dominan pada aliran sungai sedangkan spesies E. variegata lebih menyebar pada area sekitar aliran sungai. Orthetrum sabina ditemukan hampir di semua habitat kecuali pada habitat kebun kopi dengan indeks 17,24 $\%$ pada habitat sungai tanpa kanopi. O. sabina cenderung dijumpai pada daerah yang terpapar sinar matahari langsung. Menurut Mitra (2013), spesies ini dapat hidup hampir di semua habitat berair sampai ketinggian 2300 m dpl seperti kolam, rawa, danau, irigasi dan habitat berair lainnya serta toleran terhadap salinitas tinggi dan habitat yang terganggu.

Kelimpahan terendah $1,33 \%$ terjadi pada spesies Drepanosticta spatulifera di habitat Sungai berkanopi dan teramati saat sore hari. Dow (2009a) menyatakan bahwa spesies tersebut dijumpai pada ketinggian 700$800 \mathrm{~m}$ dpl di Jawa. Menurut Lieftinck (1934) $D$. spatulifera hanya ditemukan di gunung Slamet sisi selatan pada aliran sungai kecil dalam hutan.

Tabel 1. Komposisi spesies capung di Wana Wisata Curug Semirang

\begin{tabular}{|c|c|c|c|c|c|c|c|c|c|}
\hline \multirow{2}{*}{$\begin{array}{c}\text { Sub Ordo } \& \\
\text { Famili }\end{array}$} & \multirow{2}{*}{ Spesies } & \multirow{2}{*}{$\begin{array}{r}\text { Pagi } \\
\text { St } 1\end{array}$} & \multicolumn{7}{|c|}{ Sore } \\
\hline & & & St 2 & St 3 & St 4 & St 1 & St 2 & St 3 & St 4 \\
\hline \multicolumn{10}{|l|}{ Zygoptera } \\
\hline Calopterygidae & Vestalis luctuosa & 38,88 & 51,72 & 22,72 & 17,80 & 32,43 & 61,29 & 10,25 & 9,33 \\
\hline Chlorocyphidae & Heliocypha fenestrata & 5,55 & & & & & & & \\
\hline Coenagrionidae & Pericnemis stictica & & & 2,27 & & & & & \\
\hline Euphaeidae & Euphaea variegata & 11,11 & 24,13 & 11,36 & 16,43 & 35,13 & 32,25 & 20,51 & 16 \\
\hline Platycnemididae & Coeliccia membranipes & & & 22,72 & 17,80 & & & 28,20 & 5,33 \\
\hline \multirow[t]{2}{*}{ Platystictidae } & Drepanosticta spatulifera & & & & & & & & 1,33 \\
\hline & Drepanosticta sundana & 44,44 & & 6,81 & 1,36 & 24,32 & & & 2,66 \\
\hline \multicolumn{10}{|l|}{ Anisoptera } \\
\hline Corduliidae & Idionyx montana & & 3,44 & & & & & 5,12 & \\
\hline Gomphidae & Gomphus sp. & & & & 1,36 & & & & \\
\hline \multirow[t]{7}{*}{ Libellulidae } & Neurothemis terminata & & 3,44 & & & & & & \\
\hline & Orthetrum glaucum & & & & 5,47 & & & & 2,66 \\
\hline & Orthetrum pruinosum & & & & 2,73 & & & & 2,66 \\
\hline & Orthetrum sabina & & 17,24 & 11,36 & 9,58 & 8,10 & 6,45 & 7,69 & 12 \\
\hline & Orthetrum testaceum & & & 9,09 & 6,84 & & & 10,25 & 5,33 \\
\hline & Pantala flavescens & & & & & & & & 4 \\
\hline & Zygonyx ida & & & 11,36 & 19,17 & & & 17,94 & 38,66 \\
\hline \multirow[t]{3}{*}{ Macromiidae } & Macromia westwoodii & & & 2,27 & 1,36 & & & & \\
\hline & Keanekaragaman (H') & 1,13 & 1,21 & 1,98 & 2,07 & 1,28 & 0,84 & 1,80 & 1,92 \\
\hline & Pemerataan (e) & 0,81 & 0,75 & 0,90 & 0,86 & 0,92 & 0,76 & 0,92 & 0,80 \\
\hline
\end{tabular}

Keterangan :

Dominan $\mathrm{Di}>10 \%$

Sub Dominan 3,2 \% < Di $>9,9 \%$

Receden $1 \%<\mathrm{Di}>3,1 \%$

Subreceden $0,32 \%<\mathrm{Di}>0,99 \%$

Sporadis $\mathrm{Di}<0,32 \%$

Keanekaragaman tinggi jika nilai H'> 3,

Keanekaragaman sedang jika nilai $\mathrm{H}^{\prime} 1 \leq 3$,

Keanekaragaman rendah jika nilai $\mathrm{H}^{\prime}<1$.

Pemerataan tinggi jika $\mathrm{e} \geq 0,6$

Pemerataan sedang jika $0,4<\mathrm{e}<0,6$

Pemerataan rendah jika e $\leq 0,4$ 
Secara umum keanekaragaman capung di WWCS termasuk kategori sedang, kecuali pada stasiun penelitian 2 pengamatan sore. Keanekaragaman spesies dengan nilai tertinggi terdapat pada habitat Sungai berkanopi pada pagi yaitu 2,07, sedangkan keanekaragaman spesies capung terendah terjadi pada habitat sungai tanpa kanopi pada sore hari yaitu 0,84 .

Stasiun penelitian 4 merupakan habitat sungai berkanopi yang terletak didekat curug (air terjun) Semirang, pada pengamatan pagi dan sore didapatkan 13 spesies capung. Variasi habitat seperti sungai jeram berbatu, hutan sekunder dengan beragam vegetasi menjadi faktor yang menunjang keanekaragaman spesies capung pada stasiun penelitian 4. Disamping menunjang keanekaragaman spesies capung, variasi habitat tersebut menimbulkan variasi pakan / mangsa bagi capung sehingga populasi dan spesies capung pada habitat tersebut juga tinggi. Meskipun mangsa pada habitat tersebut tinggi, predator bagi capung juga terbilang tinggi. Hal ini menjadi salah satu pengendali populasi capung pada habitat sungai ternaungi sehingga keanekaragaman spesiesnya masuk dalam kategori sedang. Minimnya cemaran juga merupakan salah satu faktor penunjang keanekaragaman tersebut.

Habitat sungai tanpa kanopi memiliki habitat yang kurang bervariasi karena disekitar sungai hanya terdapat vegetasi kebun pada dan semak sehingga perolehan jumlah spesies capung pagi dan sore sedikit yaitu 5 spesies. Salah satu sebab rendahnya keanekaragaman pada stasiun pengamatan 2 karena pada habitat tersebut di dominasi oleh tiga spesies yaitu Vestalis luctuosa, Euphaea variegata dan Orthetrum sabina sehingga spesies yang lain menjadi spesies minoritas pada habitat tersebut.

Hasil Uji t-Hutchinson yaitu perbandingan antar stasiun penelitian menunjukan tidak adanya perbedaan yang nyata pada stasiun penelitian 1 dan 2 pada pagi dan stasiun penelitian 3 dan 4 pada pagi dan sore, nilai t-hitung yang didapatkan pada semua stasiun $<2.01$ pada tabel t. Hal ini dapat dilihat dari komposisi spesies pada stasiun 1 dan 2 pada pagi serta 3 dan 4 pada pagi dan sore cenderung memiliki banyak kesamaan daripada perbedaan spesiesnya.

Pemerataan spesies capung di Wana Wisata Curug Semirang memiliki indeks pemerataan dengan kategori tinggi karena melebihi 0,6. Hal ini disebabkan oleh habitat yang relatif sama yaitu adanya aliran sungai dan vegetasi disekitar aliran sungai ditiap stasiun sehingga capung dapat mempertahankan diri dari ancaman predator dan kompetitor serta dapat mempertahankan populasinya.

Menurut Santoso (2005) terdapat ketentuan terkait korelasi Spearman yaitu jika nilai 0 maka tidak terdapat korelasi, jika nilai 1 maka terdapat korelasi yang sempurna; jika nilai korelasi bertanda negatif (-) menandakan adanya arah hubungan yang berlawanan yang berarti adanya korelasi yang negatif, begitu pula sebaliknya. 
Tabel 2. Korelasi Spearman (Spearman Rank-Order Correlation Coefficient) variabel biotik dan abiotik

\begin{tabular}{|c|c|c|c|c|c|}
\hline & Kelembaban & \multicolumn{2}{|c|}{ Intensitas cahaya } & Suhu & Kecepatan Angin \\
\hline $\mathrm{H}^{\prime}$ & $-0.59^{\mathrm{s}}$ & \multicolumn{2}{|c|}{$0.04^{\mathrm{SL}}$} & $-0.07^{\mathrm{SL}}$ & $0.61^{\mathrm{K}}$ \\
\hline Jumlah Spesies & $-0.78^{\mathrm{K}}$ & \multicolumn{2}{|l|}{$0.14^{\mathrm{SL}}$} & $-0.10^{\mathrm{SL}}$ & $0.55^{\mathrm{S}}$ \\
\hline Jumlah Individu & $-0.54^{\mathrm{S}}$ & \multicolumn{2}{|l|}{$0.21^{\mathrm{L}}$} & $0.35^{\mathrm{L}}$ & $0.28^{\mathrm{L}}$ \\
\hline & \multicolumn{4}{|c|}{ Keterangan : } & \\
\hline & \multicolumn{2}{|c|}{ Interval koefisiesn korelasi $\mathrm{r}_{\mathrm{s}}$} & \multicolumn{2}{|c|}{ Tingkat hubungan } & \\
\hline & \multicolumn{2}{|l|}{$0,00-0,19:$} & \multicolumn{2}{|c|}{ Sangat Lemah (SL) } & \\
\hline & \multicolumn{2}{|l|}{$0,20-0,39:$} & & \\
\hline & \multicolumn{2}{|l|}{$0,40-0,59:$} & \multicolumn{2}{|c|}{ Sedang (S) } & \\
\hline & \multicolumn{2}{|l|}{$0,60-0,79:$} & \multicolumn{2}{|c|}{ Kuat (K) } & \\
\hline & \multicolumn{2}{|l|}{$0,80-1,00:$} & \multicolumn{2}{|c|}{ Sangat Kuat (SK) } & \\
\hline
\end{tabular}

Kelembaban berkorelasi negatif dengan indeks keanekaragaman, jumlah spesies dan jumlah individu. Suhu berkorelasi negatif dengan indeks keanekaragaman dan jumlah spesies tetapi berkorelasi positif dengan jumlah individu. Intensitas cahaya dan kecepatan angin menunjukan hubungan korelasi yang positif terhadap indeks keanekaragaman, jumlah spesies dan jumlah individu. Korelasi antara kecepatan angin terhadap indeks keanekaragaman menunjukan hubungan yang kuat. Semakin tinggi nilai korelasi menandakan adanya hubungan yang semakin kuat antara dua variabel

\section{KESIMPULAN}

Keanekaragaman spesies capung di kawasan Wana Wisata Curug Semirang termasuk kategori sedang, indeks tertinggi terdapat pada habitat Sungai berkanopi 2,07 pada pengamatan pagi, habitat Sungai tanpa kanopi termasuk kategori keanekaragaman jenis rendah pada pengamatan sore yaitu 0,84. Spesies Euphaea variegata dan Vestalis luctuosa secara umum mendominasi di semua stasiun penelitian. Indeks kelimpahan terendah 1,33 yaitu pada Drepanosticta spatulifera.

Komposisi spesies capung di WWCS bervariasi, secara umum Vestalis luctuosa, Euphaea variegata, Drepanosticta sundana dan Orthetrum sabina mendominasi karena ditemukan hampir di semua habitat. Terdapat pula spesies yang spesifik hidup pada satu tipe habitat tertentu seperti Heliocypha fenestrata, Pericnemis stictica, Drepanosticta spatulifera, Gomphus sp.,
Neurothemis terminata, Orthetrum glaucum, Orthetrum pruinosum dan Pantala flavescens.

\section{DAFTAR PUSTAKA}

Dow, R.A. 2009a. Drepanosticta spatulifera. The IUCN Red List of Threatened Species 2009: e.T163820A5656272. http://dx.doi.org/10.2305/IUCN.UK.20092.RLTS.T163820A5656272.en. Diakses pada 09 Desember 2016.

. 2009b. Idionyx montana. The IUCN Red List of Threatened Species 2009: e.T163818A5655984. http://dx.doi.org/10.2 305/IUCN.UK.2009-

2.RLTS.T163818A5655984.en. Diakses pada 02 Desember 2016.

Herlambang, A.E.N., M. Hadi \& U. Tarwotjo. 2016. Struktur Komunitas Capung di Kawasan Wisata Curug Lawe Benowo Ungaran Barat. Bioma 2016. Universitas Diponegoro. Semarang. Vol. 18, No. 1, Hal. 70-78. ISSN : 1410-8801

Irawan, F \& M. Hadi. 2015. Inventarisasi Anggota Ordo Odonata Di Kawasan Wana Wisata Curug Semirang Kecamatan Ungaran Barat, Semarang. Prosiding Seminar Nasional Biologi II 2015. Pemanfaatan Sumberdaya Hayati dan Peningkatan Kualitas Lingkungan. Magister Biologi Fakultas Sains dan Matematika Universitas Diponegoro. Semarang.

Lieftinck, M.A. 1934. An Annotated List of the Odonata of Java, with Notes on Their Distribution , Habits and Life-History. Zoologisch Museum. Buitenzorg, Java. 
Mitra, A. 2013. Orthetrum sabina. The IUCN Red List of Threatened Species 2013: e.T165470A17533255. http://dx.doi.org/10. 2305/IUCN.UK.20131.RLTS.T165470A17 533255.en. Diakses pada 09 Desember 2016.

Odum, E.P. 1971. Fundamentals of Ecology. Philadelphia. Saunders.

Rizal, S. 2014. Struktur Komunitas Capung (Insecta: Odonata) di Sekitar Ekosistem Danau Rawa Pening. Skripsi. Universitas Diponegoro. Semarang.
Santoso, S. 2005. Menguasai Statistik di Era Informasi dengan SPSS 12. Elex Media Komputindo. Jakarta.

Whitten, T., Roehayat, E.S., \& Suraya, A.A. 1999. Ekologi Jawa dan Bali. Prenhallindo. Jakarta. 